\title{
Epistaxis, CTCAE
}

National Cancer Institute

\section{Source}

National Cancer Institute. Epistaxis, CT CAE. NCI Thesaurus. Code C143447.

A disorder characterized by bleeding from the nose. 